\title{
Outcome of intracerebral hemorrhage associated with different oral anticoagulants OPEN :
}

Duncan Wilson, MD

David J. Seiffge, MD

Christopher Traenka, MD

Ghazala Basir, MBBS, FCPS

Jan C. Purrucker, MD

Timolaos Rizos, MD

Oluwaseun A. Sobowale, MD

Hanne Sallinen, MD

Shin-Joe Yeh, MD

Teddy Y. Wu, MD

Marc Ferrigno, MD

Rik Houben, MD

Floris H.B.M. Schreuder, $\mathrm{MD}$

Luke A. Perry, BSc

Jun Tanaka, MD

Marion Boulanger, MD

Rustam Al-Shahi Salman,

FRCP Edin

Hans R. Jäger, MD,

FRCR

Gareth Ambler, PhD

Clare Shakeshaft, MSc

Yusuke Yakushiji, MD

Philip M.C. Choi,

MBChB, FRACP

Julie Staals, MD, PhD

Charlotte Cordonnier, MD

Jiann-Shing Jeng, MD, $\mathrm{PhD}$

Roland Veltkamp, MD

Dar Dowlatshahi, MD, $\mathrm{PhD}$

Stefan T. Engelter, MD

Adrian R. Parry-Jones, $\mathrm{PhD}$

Atte Meretoja, MD, PhD, MSc

David J. Werring, PhD

And the CROMIS-2 collaborators

\section{ABSTRACT}

Objective: In an international collaborative multicenter pooled analysis, we compared mortality, functional outcome, intracerebral hemorrhage $(\mathrm{ICH})$ volume, and hematoma expansion (HE) between non-vitamin $\mathrm{K}$ antagonist oral anticoagulation-related $\mathrm{ICH}(\mathrm{NOAC}-\mathrm{ICH})$ and vitamin $\mathrm{K}$ antagonist-associated ICH (VKA-ICH).

Methods: We compared all-cause mortality within 90 days for $\mathrm{NOAC}-\mathrm{ICH}$ and VKA-ICH using a Cox proportional hazards model adjusted for age; sex; baseline Glasgow Coma Scale score, $\mathrm{ICH}$ location, and log volume; intraventricular hemorrhage volume; and intracranial surgery. We addressed heterogeneity using a shared frailty term. Good functional outcome was defined as discharge modified Rankin Scale score $\leq 2$ and investigated in multivariable logistic regression. ICH volume was measured by $\mathrm{ABC} / 2$ or a semiautomated planimetric method. $\mathrm{HE}$ was defined as an $\mathrm{ICH}$ volume increase $>33 \%$ or $>6 \mathrm{~mL}$ from baseline within 72 hours.

Results: We included 500 patients (97 NOAC-ICH and $403 \mathrm{VKA}-\mathrm{ICH}$ ). Median baseline ICH volume was 14.4 mL (interquartile range [IQR] 3.6-38.4) for NOAC-ICH vs 10.6 mL (IQR 4.0-27.9) for VKA$\mathrm{ICH}(p=0.78)$. We did not find any difference between $\mathrm{NOAC}-\mathrm{ICH}$ and VKA-ICH for all-cause mortality within 90 days (33\% for NOAC-ICH vs 31\% for VKA-ICH [p = 0.64]; adjusted Cox hazard ratio (for NOAC-ICH vs VKA-ICH) 0.93 [95\% confidence interval (CI) 0.52-1.64] [p $=0.79]$ ), the rate of HE (NOAC-ICH $n=29 / 48$ [40\%] vs VKA-ICH $n=93 / 140$ [34\%] [p = 0.45]), or functional outcome at hospital discharge (NOAC-ICH vs VKA-ICH odds ratio 0.47; 95\% Cl 0.18-1.19 [p = 0.11]).

Conclusions: In our international collaborative multicenter pooled analysis, baseline ICH volume, hematoma expansion, 90-day mortality, and functional outcome were similar following NOACICH and VKA-ICH. Neurology ${ }^{\circledR}$ 2017;88:1693-1700

\section{GLOSSARY}

$\mathbf{A F}=$ atrial fibrillation; $\mathbf{C I}$ = confidence interval; $\mathbf{G C S}=$ Glasgow Coma Scale; $\mathbf{H E}=$ hematoma expansion; $\mathbf{H R}=$ hazard ratio; $\mathbf{I C H}=$ intracerebral hemorrhage; INR = international normalized ratio; IQR = interquartile range; IVH = intraventricular hemorrhage; $\mathbf{m R S}=$ modified Rankin Scale; $\mathbf{N O A C}=$ non-vitamin $\mathrm{K}$ antagonist oral anticoagulant; $\mathbf{O A C}=$ oral anticoagulant; PCC $=$ prothrombin complex concentrate; VKA = vitamin $\mathrm{K}$ antagonist.

Randomized trials in patients with atrial fibrillation (AF) show that direct (non-vitamin $\mathrm{K}$ antagonist [VKA]) oral anticoagulants (NOACs) have about half the incidence of intracerebral hemorrhage (ICH) compared to VKA but with a similar efficacy in preventing ischemic stroke. ${ }^{1}$ Nevertheless, there is concern that without wide access to specific reversal agents at

From the Stroke Research Center (D.W., C.S., D.J.W.) and Neuroradiological Academic Unit (H.R.J.), Department of Brain Repair and Rehabilitation, Institute of Neurology, and Department of Statistical Science (G.A.), UCL, London, UK; Stroke Center and Neurology (D.J.S., C.T., S.T.E.), University Hospital Basel, University of Basel, Switzerland; Ottawa Hospital Research Institute and University of Ottawa (G.B., D.D.), Canada; Department of Neurology (J.C.P., T.R.), Heidelberg University Hospital, Germany; Manchester Academic Health Sciences Center (O.A.S., A.R.P.-J.), Salford Royal NHS Foundation Trust, UK; Department of Neurology (H.S., A.M.), Helsinki University Hospital, Finland; Stroke Center \& Department of Neurology (S.-J.Y., J.-S.J.), Department of Neurology, National Taiwan University Hospital, Taipei; Department of Medicine and neurology at the Royal Melbourne Hospital (T.Y.W., A.M.), University of Melbourne, Parkville, Australia; U1171-Degenerative \& Vascular Cognitive Disorders (M.F., C.C.), Univ Lille, Inserm, CHU Lille, France; Department of Neurology (R.H., F.H.B.M.S., J.S.), Maastricht University Medical Center, the Netherlands; Department of Neurosciences (J.A.P., P.M.C.C.), Eastern Health, Melbourne, Australia; Division of Neurology, Department of Internal Medicine (J.T., Y.Y.), Saga University Faculty of Medicine, Japan; Division of Clinical Neurosciences (M.B., R.A.-S.S.), Center for Clinical Brain Sciences, School of Clinical Sciences, University of Edinburgh; Department of Stroke Medicine, Division of Brain Sciences (R.V.), Imperial College London, UK; and Neurorehabilitation Unit (S.T.E.), University of Basel and University Center for Medicine of Aging, Felix Platter Hospital, Switzerland.

Coinvestigators are listed at Neurology.org.

Go to Neurology.org for full disclosures. Funding information and disclosures deemed relevant by the authors, if any, are provided at the end of the article. The Article Processing Charge was funded by British Heart Foundation.

This is an open access article distributed under the terms of the Creative Commons Attribution License 4.0 (CC BY), which permits unrestricted use, distribution, and reproduction in any medium, provided the original work is properly cited. 
Correspondence to

David J. Werring:

d.werring@ucl.ac.uk

Editorial, page 1686

Supplemental data at Neurology.org the time of this study, NOAC-associated $\mathrm{ICH}$ (NOAC-ICH) might be larger, with a higher risk of hematoma expansion (HE) and worse outcome, than VKA-associated $\mathrm{ICH}$ (VKA-ICH), for which reversal strategies are established. ${ }^{2-4}$

There are few data on the clinical and radiologic characteristics or the functional outcome of NOAC-ICH to guide clinicians. A multicenter prospective study of 61 patients with NOAC-ICH reported $28 \%$ mortality at 90 days, but with no comparison to VKA-ICH. ${ }^{5}$ Subanalyses of the RE-LY, ARISTOTLE, and ROCKET-AF trials ${ }^{6-8}$ suggest similar mortality for VKA-ICH and NOAC-ICH. However, a single-center study from Japan (NOAC$\mathrm{ICH}, \mathrm{n}=5$ ) and a small multicenter study from the United Kingdom (NOAC-ICH, $\mathrm{n}=$ 11) both found that hematoma volume was smaller in NOAC-ICH compared to VKA$\mathrm{ICH},{ }^{9,10}$ with better or similar functional outcome at hospital discharge.

We undertook an international, collaborative, multicenter, pooled individual patient data analysis to systematically describe the clinical and radiologic characteristics and outcome of NOAC-ICH in comparison to VKA$\mathrm{ICH}$.

METHODS We identified relevant cohorts from an international multicenter collaboration. ${ }^{4}$ To reduce bias and confounding due to secular trends in ICH treatment (including anticoagulation reversal strategies), we only included VKA-ICH data after the date of diagnosis of the first included NOAC-ICH at each center, according to a prespecified protocol. Inclusion criteria were as follows: ICH while on oral anticoagulation (NOAC-ICH or VKA-ICH); age over 18 years; for VKA-ICH, international normalized ratio (INR) on hospital admission $\geq 1.3$; for NOAC-ICH, known NOAC use within 24 hours prior to ICH clinical symptoms. Exclusion criteria were as follows: secondary cause for ICH (such as major head trauma in the previous 24 hours, vascular malformations, tumors, cavernomas, aneurysms, other known coagulopathy, or hemorrhagic transformation of an infarct); or predominant subarachnoid hemorrhage. The primary outcome was mortality by 90 days, adjusted for potential confounding baseline characteristics. Secondary outcomes were ICH volume at baseline, proportion of patients with HE, and functional outcome measured by the modified Rankin Scale (mRS) at discharge. Some patient data from previously published studies ${ }^{5,10}$ were included (NOAC, $\mathrm{n}=33$; VKA, $\mathrm{n}=52$ ).

Clinical and imaging data analysis. We collected clinical, demographic, and imaging data using a standardized data collection form. Imaging data included baseline $\mathrm{ICH}$ volume measured from the first available $\mathrm{CT}$ scan, using either $\mathrm{ABC} / 2$ or semiautomated planimetric measurement, blinded to anticoagulant type and outcome in all but 3 centers; hematoma location (lobar, supratentorial deep [basal ganglia and thalamus], brainstem, or cerebellar); intraventricular hemorrhage (IVH) volume determined using a semiautomated planimetric method or the modified Graeb or Hallevi scales ${ }^{4,11,12}$; and HE, defined as an increase in volume by $>33 \%$ or $>6 \mathrm{~mL}$ from the baseline scan within 72 hours in patients with their first scan within 6 hours of symptom onset and without subsequent intracranial surgery before follow-up imaging, in keeping with a recent collaboration $^{4}$ and validation. ${ }^{13}$

Statistical analysis. D.W., D.J.W., A.R.P.-J., and A.M. wrote a prespecified statistical analysis plan, which was approved by all participating centers. We compared patient characteristics between the VKA-ICH and NOAC-ICH groups using appropriate analysis for categorical and continuous variables. We visually inspected the distribution of the continuous variables using histograms, summarized as medians with interquartile range (IQR). Differences between the groups were determined using the Mann-Whitney test (if not normally distributed); categorical variables between the groups were compared with the $\chi^{2}$ test. We log-transformed variables that were not normally distributed. For IVH volume (where the majority of patients had $0 \mathrm{~mL}$ ), we modeled using 2 variables: an indicator to model those with no IVH and a log-transformed variable for those with IVH, allowing us to generate a hazard ratio (HR) for each milliliter increase of IVH volume. Univariate Kaplan-Meier estimates were used to estimate survival probabilities by 90 days for each anticoagulant group; the log-rank test was used to compare groups.

Required sample sizes were estimated using a previously reported convenience sample. ${ }^{4}$ Assuming 90-day mortality (primary outcome) in the VKA group to be $46 \%$, a study of 50 NOAC and 500 VKA patients has $80 \%$ power to identify a HR of 0.55 (i.e., mortality of $25 \%$ vs $46 \%$ ) with a 2 -sided $p$ value of 0.05 . For the secondary outcome of $\mathrm{ICH}$ volume, if we assume VKA-ICH median volume of $18 \mathrm{~mL}$, a study of 50 NOAC and 500 VKA patients has $80 \%$ power to identify a difference of $61 \%$ (median 18 vs $11 \mathrm{~mL}$ ) with a 2 -sided $p$ value of 0.05 . For the secondary outcome of ICH expansion, we assume expansion $(>6 \mathrm{~mL}$ or $>33 \%$ ) to occur in $60 \%$ of the VKA patients (and that only half of VKA and NOAC patients will have imaging at the required time windows); a study of 25 NOAC and 250 VKA patients has $75 \%$ power to identify a difference between $60 \%$ and $33 \%$ with a 2 -sided $p$ value of 0.05 .

Prespecified analyses. For the primary prespecified outcome analysis, we fitted a Cox proportional hazards model, adjusting for variables known to affect outcome (age, sex, baseline Glasgow Coma Scale [GCS] score, log baseline ICH volume, baseline IVH volume, ICH location, and acute neurosurgery). The assumption of proportional hazards was assessed by visual inspection of each $\log -\log$ plot of survival. Possible heterogeneity in general $\mathrm{ICH}$ management, resources, and ethnicity by site was addressed by adding a shared frailty term to the model. We performed prespecified subgroup analyses of the primary outcome measure by $\mathrm{ICH}$ location and by individual NOAC agent. A secondary analysis compared baseline ICH volume between anticoagulants using a linear regression model with log-transformed ICH volume as the dependent variable, adjusting for age and ICH location. HE (yes/no) between anticoagulant groups was investigated with logistic regression adjusting for age, ICH location, GCS, and baseline INR

Post hoc analyses. We explored functional independence at discharge using the mRS and logistic regression. Discharge $\mathrm{mRS}$ was dichotomized into $0-2$ vs 3-6 and adjusted for premorbid mRS, age, and baseline GCS. Shift analysis was the 
prespecified analysis of choice, but our data did not fulfil the proportional odds assumption. A second post hoc analysis was undertaken using data only within the first 30 days of follow-up. Furthermore, we ran individual sensitivity analyses of our primary outcome adjusting for (in addition to the pre specified variables) anticoagulation reversal with prothrombin complex concentrate (PCC) (yes/no), event to presentation time (days), adjustments for method of volume ascertainment ( $\mathrm{ABC} / 2$ vs planimetric), and whether patients came from a consecutive registry. We also undertook further sensitivity analyses. First, we included a primary outcome of mortality by 30 days (which might be more directly related to the effect of the acute $\mathrm{ICH}$ ); in this analysis, we included only age, sex, and acute neurosurgery in one model and age, sex, acute neurosurgery, ICH location, and IVH extension in another model, excluding baseline characteristics likely to be confounded by oral anticoagulant type (ICH volume, baseline GCS, IVH volume). Finally, we undertook a sensitivity analysis of mortality at 90 days to account for heterogeneity in the $\mathrm{ICH}$ volume measurement method.

Standard protocol approvals, registrations, and patient consents. This study was approved by the NHS Health Research Authority (Research Ethics Committee reference 15/YH/0475). Responsibility for ensuring compliance with local laws and data sharing policies was delegated to local principle investigators at each center, as outlined in the protocol.

RESULTS We retrospectively pooled data from 13 stroke registries from the following countries: United Kingdom $(2$ centers and a multicenter prospective observational study), Finland, the Netherlands, Switzerland, France, Germany, Canada, Australia (2 centers), Taiwan, and Japan (table 1). We identified 540 patients with oral anticoagulant (OAC)-associated ICH recruited between April 28, 2012, and August 18, 2015 (registration periods varied by center); 100 participants had NOAC-ICH and 440 had VKAICH. We excluded 40 patients (figure 1); full datasets required for the primary analysis were available for 500 participants (97 with NOAC-ICH and 403 with VKA-ICH) (figure 1). The NOACs used were apixaban $(\mathrm{n}=13)$, dabigatran $(\mathrm{n}=13)$, and rivaroxaban ( $n=69)$. Two participants were taking either rivaroxaban or apixaban. The median follow-up (accounting for deaths prior to 90 days) was 60 days (IQR 9-196) and varied by center (table 1). The onset of ICH symptoms to CT scan ranged from $<24$ hours (402 patients, $80 \%$ ) to 11 days (1 patient, $0.2 \%)$. ICH volume was rated using the $\mathrm{ABC} / 2$ method in 8 centers and a semiautomated planimetric method in 5 centers. IVH was rated using the modified Graeb method in 3 centers, the Hallevi score in 6 centers, and a semiautomated planimetric method in 4 centers. The median INR value within the VKAICH group was 2.7 (IQR 2.2-3.4). The underlying indication for anticoagulation was known in 415/500

Table 1 Study characteristics by center

\begin{tabular}{|c|c|c|c|c|c|c|c|}
\hline Center/registry & $\begin{array}{l}\text { Years of } \\
\text { recruitment }\end{array}$ & $\begin{array}{l}\text { Observed deaths } \\
\text { within } 90 \mathrm{~d}, \mathrm{n}(\%)^{\mathrm{a}}\end{array}$ & $\begin{array}{l}\text { NOAC- } \\
\text { ICH, n }\end{array}$ & $\begin{array}{l}\text { VKA- } \\
\text { ICH, n }\end{array}$ & $\begin{array}{l}\mathrm{ICH} \text { volume } \\
\text { rating method }\end{array}$ & $\begin{array}{l}\text { IVH rating } \\
\text { method }\end{array}$ & $\begin{array}{l}\text { Retrospective/prospective; } \\
\text { consecutive/nonconsecutive }\end{array}$ \\
\hline Box Hill Hospital, Australia & 2014-2015 & $4(44)$ & 5 & 4 & $\mathrm{ABC} / 2$ & Hallevi & Retrospective, consecutive \\
\hline $\begin{array}{l}\text { Maastricht University } \\
\text { Medical Center, } \\
\text { Netherlands }\end{array}$ & 2014-2015 & $10(71)$ & 2 & 12 & $\mathrm{ABC} / 2$ & Hallevi & Prospective, consecutive \\
\hline $\begin{array}{l}\text { Manchester Academic } \\
\text { Health Sciences Center, } \\
\text { Salford, UK }\end{array}$ & 2013-2015 & $20(75)$ & 5 & 30 & Semiplanimetric & Semiplanimetric & Prospective, consecutive \\
\hline $\begin{array}{l}\text { National Taiwan University } \\
\text { Hospital }\end{array}$ & 2013-2015 & 7 (39) & 6 & 12 & $\mathrm{ABC} / 2$ & Hallevi & Prospective, consecutive \\
\hline Univ Lille, France & 2013-2015 & $4(27)$ & 3 & 12 & $\mathrm{ABC} / 2$ & Hallevi & Prospective, consecutive \\
\hline $\begin{array}{l}\text { Helsinki University Hospital, } \\
\text { Finland }\end{array}$ & 2014 & 5 (28) & 2 & 16 & Semiplanimetric & Semiplanimetric & Retrospective, consecutive \\
\hline $\begin{array}{l}\text { University Hospital Basel, } \\
\text { Switzerland }\end{array}$ & 2012-2015 & $19(40)$ & 21 & 27 & $\mathrm{ABC} / 2$ & Graeb & Prospective, consecutive \\
\hline $\begin{array}{l}\text { Ottawa Hospital Research } \\
\text { Institute, Canada }\end{array}$ & 2011-2015 & $20(42)$ & 4 & 44 & $\mathrm{ABC} / 2$ & Hallevi & Retrospective, consecutive \\
\hline $\begin{array}{l}\text { Lothian Cerebral } \\
\text { Hemorrhage Registry, } \\
\text { Edinburgh, UK }\end{array}$ & 2014-2015 & $4(80)$ & 2 & 3 & $\mathrm{ABC} / 2$ & Graeb & Prospective, nonconsecutive \\
\hline $\begin{array}{l}\text { Royal Melbourne Hospital, } \\
\text { Australia }\end{array}$ & 2014-2015 & $7(41)$ & 4 & 13 & Semiplanimetric & Semiplanimetric & Retrospective, consecutive \\
\hline $\begin{array}{l}\text { Saga University Hospital, } \\
\text { Japan }\end{array}$ & 2013-2015 & $1(14)$ & 3 & 4 & $\mathrm{ABC} / 2$ & Hallevi & Prospective, consecutive \\
\hline $\begin{array}{l}\text { Heidelberg University } \\
\text { Hospital, Germany }\end{array}$ & 2012-2014 & 11 (31) & 21 & 14 & Semiplanimetric & Graeb & $\begin{array}{l}\text { Prospective, consecutive (NOAC); } \\
\text { retrospective, consecutive (VKA) }\end{array}$ \\
\hline CROMIS-2, United Kingdom & 2013-2015 & 40 (17) & 19 & 212 & Semiplanimetric & Semiplanimetric & Prospective, nonconsecutive \\
\hline
\end{tabular}

Abbreviations: $\mathrm{ICH}=$ intracerebral hemorrhage; NOAC = non-vitamin $\mathrm{K}$ antagonist oral anticoagulant; VKA = vitamin $\mathrm{K}$ antagonist.

${ }^{a}$ Not adjusted for censoring. 


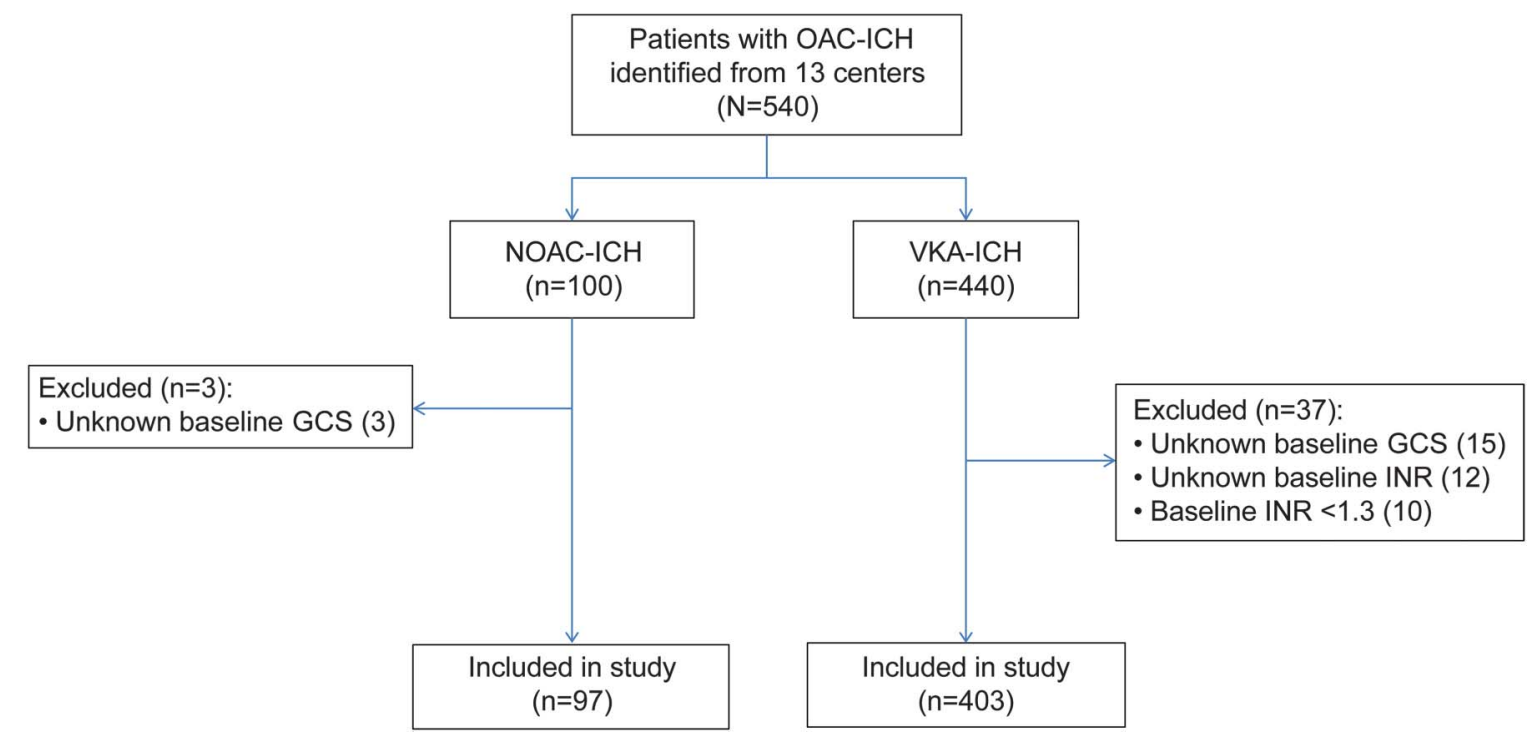

GCS = Glasgow Coma Scale; ICH = intracerebral hemorrhage; INR = international normalized ratio; NOAC = non-vitamin K antagonist oral anticoagulant; $\mathrm{OAC}=$ oral anticoagulation; $\mathrm{VKA}=$ vitamin $\mathrm{K}$ antagonist anticoagulant.

patients, as follows: 370 (89\%) for AF, 28 (6.7\%) for deep vein thrombosis/pulmonary embolism, 15 (3.6\%) for mechanical heart valves, and $2(0.5 \%)$ for cardiomyopathy. All but 1 of these patients was on a VKA.

The patient characteristics for NOAC-ICH and VKA-ICH are shown in table 2; those with NOAC-ICH more often had cerebellar ICH and

\begin{tabular}{|c|c|c|c|}
\hline Table 2 & \multicolumn{3}{|c|}{$\begin{array}{l}\text { Characteristics of participants with non-vitamin } \mathrm{K} \text { antagonist oral } \\
\text { anticoagulant (NOAC)-associated intracerebral hemorrhage (ICH) and } \\
\text { vitamin K antagonist (VKA)-associated ICH }\end{array}$} \\
\hline \multicolumn{2}{|l|}{ Variable } & NOAC-ICH $(n=97)$ & VKA-ICH $(n=403)$ \\
\hline \multicolumn{2}{|c|}{ Age, y, median (IQR) } & $80(74-85)$ & $80(72-85)$ \\
\hline \multicolumn{2}{|c|}{ Male sex, $\mathrm{n}(\%)$} & $53(55)$ & $196(49)$ \\
\hline \multicolumn{4}{|c|}{$\mathrm{ICH}$ location } \\
\hline \multicolumn{2}{|c|}{ Lobar area } & 38 (39) & $158(39)$ \\
\hline \multicolumn{2}{|c|}{ Supratentorial deep areas } & $40(41)$ & $198(49)$ \\
\hline \multicolumn{2}{|c|}{ Cerebellum } & $13(13)$ & $26(6)$ \\
\hline \multicolumn{2}{|c|}{ Brainstem } & $6(6)$ & $21(5)$ \\
\hline \multicolumn{2}{|c|}{ Glasgow Coma Scale, median (IQR) } & $14(12-15)$ & $15(13-15)$ \\
\hline \multicolumn{2}{|c|}{ Acute neurosurgery, $\mathrm{n}(\%)$} & $7(7)$ & $24(6)$ \\
\hline \multicolumn{2}{|c|}{ IVH extension, n (\%) } & $42(43)$ & $146(36)$ \\
\hline \multicolumn{2}{|c|}{ Premorbid mRS, median (IQR) ${ }^{\mathrm{a}}$} & $1(0-3)$ & $0(0-2)$ \\
\hline \multicolumn{2}{|c|}{ Early palliation, n (\%) } & $11(13)$ & $28(7)$ \\
\hline \multicolumn{2}{|c|}{ Anticoagulation for atrial fibrillation, $\mathrm{n}(\%)$} & $85 / 86(99)$ & 267/332 (80) \\
\hline
\end{tabular}

Abbreviations: IQR = interquartile range; IVH = intraventricular hemorrhage; $\mathrm{mRS}=$ modified Rankin Scale.

Values are $\mathrm{n}(\%)$ or median (IQR).

${ }^{\text {a }}$ Available in 431 patients. worse premorbid mRS compared with VKA-ICH, but were otherwise similar. OAC reversal information was available in 450 patients (365 VKA-ICH and 85 NOAC-ICH); of these, 286/365 (78\%) participants with VKA-ICH received 3 or 4 factor PCC, compared to $35 / 85$ (41\%) of participants with NOAC-ICH $(p \leq 0.001)$. Twenty-four patients with VKA-ICH (6\%) and 7 patients with $\mathrm{NOAC}-\mathrm{ICH} \quad(7 \%)$ were treated with acute neurosurgery.

Primary outcome. There were 161 deaths (a crude mortality rate of $32 \%)$. After adjusting for censoring, all-cause mortality was $31 \%$ at 90 days. Ninety-day mortality was $33 \%$ (95\% confidence interval [CI] 24-44) for NOAC-ICH vs 31\% (95\% CI 27-37) for VKA-ICH $(p=0.64)$. Age, admission GCS, and $\mathrm{ICH}$ volume were associated with 90-day mortality in univariable analysis (table 3). After adjusting for baseline variables (age, sex, baseline GCS, log baseline ICH volume, baseline IVH volume, ICH location, and acute neurosurgery) and addressing heterogeneity by site (using a shared frailty term), there was no difference in survival between NOAC-ICH and VKA-ICH (HR 0.93; 95\% CI 0.52-1.64; $p=0.79$ ) (figure 2 and table 3 ). In post hoc analyses, the primary result was unchanged as follows: PCC treatment (HR 0.99; 0.57-1.72), ICH onset to presentation time (HR 0.81; 95\% CI 0.49-1.35), ICH volume measurement method (HR 0.80; 95\% CI $0.48-$ 1.35), and consecutive registry source (HR 0.84; 95\% CI $0.50-1.38$ ). There was no between-group difference in 30-day mortality (HR NOAC-ICH vs VKA-ICH 0.83 ; $95 \%$ CI $0.47-1.48 ; p=0.53$ ) or 


\begin{tabular}{|c|c|c|c|c|c|}
\hline \multirow{3}{*}{$\begin{array}{l}\text { Table } 3 \\
\text { Variables }\end{array}$} & \multicolumn{5}{|c|}{$\begin{array}{l}\text { Cox proportional hazards models: univariable and multivariable analyses for the primary outcome of } \\
\text { 90-day mortality }\end{array}$} \\
\hline & \multirow[b]{2}{*}{ Units } & \multicolumn{2}{|l|}{ Univariable model } & \multicolumn{2}{|l|}{ Multivariable model } \\
\hline & & $\mathrm{HR}(95 \% \mathrm{Cl})$ & $p$ Value & HR $(95 \% \mathrm{Cl})$ & $p$ Value \\
\hline \multirow[t]{2}{*}{ Sex } & Female & 1.00 (reference) & & 1.00 (reference) & \\
\hline & Male & $1.08(0.77-1.51)$ & 0.65 & $0.92(0.68-1.32)$ & 0.654 \\
\hline Age & Per year & $1.04(1.02-1.06)$ & 0.001 & $1.04(1.01-1.06)$ & 0.002 \\
\hline GCS & Per point & $0.81(0.78-0.85)$ & 0.001 & $0.85(0.80-0.89)$ & 0.001 \\
\hline $\mathrm{ICH}$ volume & Per (log) $\mathrm{mL}$ & $1.58(1.38-1.82)$ & 0.001 & $1.38(1.17-1.64)$ & 0.001 \\
\hline IVH volume & Per (log) $\mathrm{mL}$ & $1.525(1.37-1.70)$ & 0.001 & $1.18(0.98-1.44)$ & 0.081 \\
\hline \multirow[t]{4}{*}{ ICH location } & Lobar area & 1.00 (reference) & & 1 (reference) & \\
\hline & Supratentorial deep areas & $0.94(0.67-1.32)$ & 0.74 & $1.26(0.83-1.90)$ & 0.277 \\
\hline & Cerebellum & $0.73(0.36-1.49)$ & 0.39 & $1.31(0.59-2.93)$ & 0.514 \\
\hline & Brainstem & $0.94(0.42-2.14)$ & 0.89 & $3.36(1.30-8.70)$ & 0.012 \\
\hline Neurosurgery & vs no neurosurgery & $0.84(0.41-1.71)$ & 0.63 & $0.45(0.20-1.00)$ & 0.051 \\
\hline \multirow[t]{2}{*}{ Anticoagulant type } & VKA & 1.00 (reference) & & 1 (reference) & \\
\hline & NOAC & $1.10(0.73-1.67)$ & 0.65 & $0.93(0.52-1.64)$ & 0.792 \\
\hline
\end{tabular}

Abbreviations: $\mathrm{Cl}$ = confidence interval; GCS = Glasgow Coma Scale; $\mathrm{HR}=$ hazard ratio; ICH = intracerebral hemorrhage; $\mathrm{IVH}=$ intraventricular hemorrhage; NOAC = non-vitamin $\mathrm{K}$ antagonist oral anticoagulant; VKA = vitamin $\mathrm{K}$ antagonist.

60-day mortality (HR NOAC-ICH vs VKA-ICH 0.75 ; $95 \%$ CI $0.44-1.30 ; p=0.308)$.

For the outcome of mortality by 30 days (including age, sex, acute neurosurgery in model 1 and age, sex, acute neurosurgery, ICH location, and IVH extension as covariates in model 2) the main result was unchanged (HR for NOAC-ICH

Figure 2 Survival curve comparing non-vitamin K oral antagonist anticoagulant (NOAC)-associated intracerebral hemorrhage (ICH) and vitamin $\mathrm{K}$ antagonist anticoagulant (VKA)-associated ICH 90-day mortality

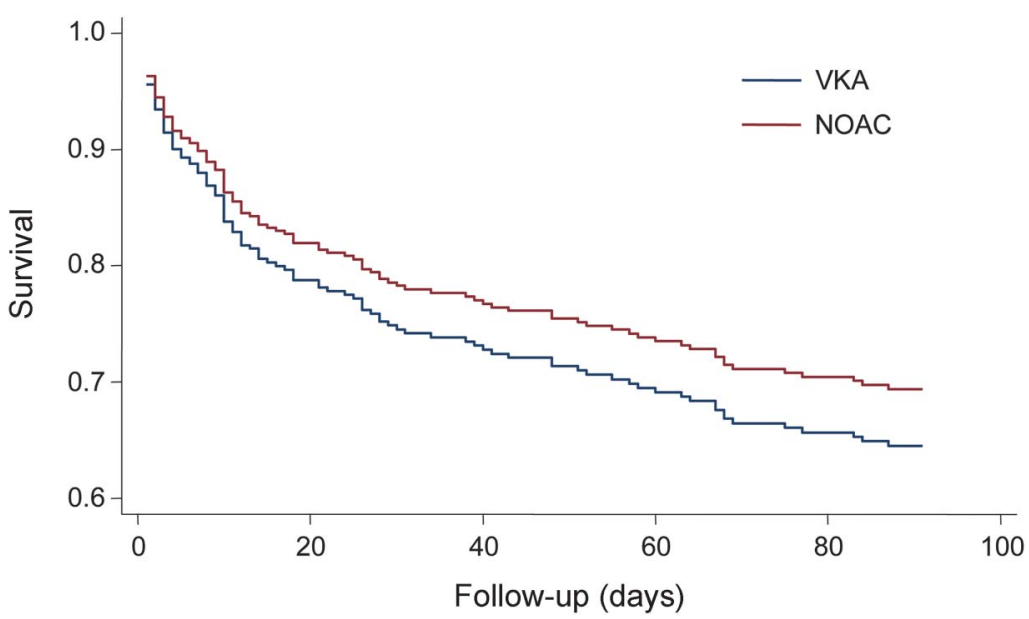

Number at risk

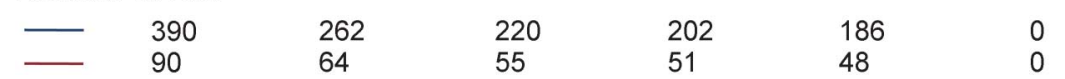

Adjusted for age; sex; baseline Glasgow Coma Scale score, ICH location, and log volume; intraventricular hemorrhage volume; and intracranial surgery. vs VKA-ICH 0.88 [95\% CI 0.53-1.45] for model 1 and 0.94 [95\% CI 0.55-1.59] [ $p=0.813$ ] for model 2) (supplemental data at Neurology.org). In sensitivity analyses for the outcome of mortality by 90 days including $\log \mathrm{ICH}$ volume assessed by different methods ( $\mathrm{ABC} / 3$, planimetry), the main result for NOAC-ICH vs VKA-ICH also remained unchanged (see supplemental data).

Secondary outcomes. Median baseline VKA-ICH volume was $10.6 \mathrm{~mL}$ (IQR 4.0-27.9), compared to $14.4 \mathrm{~mL}$ (IQR 3.6-38.4) for NOAC-ICH ( $p=$ $0.78)$. There was no statistical difference in logtransformed ICH volumes in multivariable linear regression (coefficient $0.06 ; 95 \% \mathrm{CI}-0.28$ to $0.41, p=0.72)$. Data regarding HE were available in 188 patients (140 [35\%] VKA-ICH and 48 [49\%] NOAC-ICH), and did not vary by anticoagulant type (NOAC-ICH 29/48 40\% vs VKA$\mathrm{ICH} 93 / 14034 \%, p=0.45$ ); there was no between-group difference in $\mathrm{HE}$ after multivariable logistic regression adjusting for age, ICH location, baseline INR, and GCS (OR 1.38; 95\% CI $0.46-4.18 ; p=0.57$ ).

Participants with VKA-ICH were more likely to be functionally independent at discharge than those with $\mathrm{NOAC}-\mathrm{ICH}$ in univariable analysis $(23 \%$ vs $10 \%$, respectively, $p<0.001$ ), but not in multivariable logistic regression after adjusting for premorbid $\mathrm{mRS}$, age, IVH extension, and baseline GCS (NOAC vs VKAICH: OR 0.47; 95\% CI 0.18-1.19; $p=0.11$ ). Backwards stepwise regression suggested that a baseline 
difference in premorbid mRS between NOAC-ICH and VKA-ICH accounts for the difference between the univariable and multivariable analysis results.

DISCUSSION Our multicenter, international individual patient pooled analysis of 500 participants with OAC-ICH found that 90-day mortality for NOAC$\mathrm{ICH}$ is similar to that for VKA-ICH. Functional outcome, ICH volume, and HE were also similar between the NOAC-ICH and VKA-ICH groups. We found no statistically significant differences between individual NOAC-ICH 90-day mortality rates, although the numbers of participants taking each individual OAC were limited. We found no significant difference between NOAC-ICH and VKA-ICH in a post hoc analysis of 30-day mortality.

Although previous small studies suggested that hematoma volume was smaller for NOAC-ICH compared to VKA-ICH, with better or similar functional outcome at hospital discharge, these included only 5 and 11 participants with NOAC-ICH, respectively, ${ }^{9,10}$ and were not statistically powered to detect differences in ICH volume or outcome. Furthermore, hospital discharge mRS might not reflect longer-term outcome and is prone to confounding by premorbid mRS. We included 90-day mortality, which more accurately reflects longer term outcome and is less prone to confounding. Although previous animal models suggest that hematoma expansion does not occur with therapeutic doses of NOACs (rivaroxaban and dabigatran), ${ }^{14,15}$ supported by small human case series $(\mathrm{n}=5$ and 6$),{ }^{9,16}$ a recent multicenter registry $(\mathrm{n}=61)$ described hematoma expansion with NOACs, ${ }^{5}$ consistent with our study. The real-world mortality we report for NOAC-ICH and VKA-ICH is in keeping with findings from the RE-LY (mortality for VKA-ICH 36\% vs dabigatran-ICH 35\% [150 $\mathrm{mg}$ ] and $41 \%$ [110 mg]), ${ }^{6,17}$ ROCKET-AF (mortality for VKA-ICH $50 \%$ vs rivaroxaban-ICH 48\%), ${ }^{7}$ and ARISTOTLE (mortality for VKA-ICH $42.3 \%$ vs apixaban-ICH $45.3 \%)^{8}$ randomized trials.

Our study has important strengths. We include a large cohort of patients with both NOAC-ICH and VKA-ICH. The use of detailed individual patient clinical and radiologic data allowed us to describe baseline characteristics and key clinically relevant outcomes beyond the acute phase of hospital admission, and to adjust for important potential confounding factors. Because we included prospectively collected clinical data from Europe, North America, East Asia, and Australasia, our findings are likely to be more generalizable to a real-life OAC-ICH population in broad range of health care settings than any of the previous studies. We reduced bias from secular treatment trends by only including $\mathrm{NOAC}-\mathrm{ICH}$ and VKA-ICH recruited during the same time period, and from the same patient population, from each participating center. Our primary outcome of 90-day mortality is unlikely to be substantially confounded by premorbid functional status.

We also acknowledge limitations: functional outcome at 90 days would have been a preferable secondary outcome to discharge mRS, as it is less confounded by length of stay, but these data were not available. We do not know how widely NOAC adoption was within each source population, which could lead to confounding by indication. Although we compared and adjusted for baseline characteristics between NOAC-ICH and VKA-ICH patients, there might be unmeasured confounding factors, including clinician judgement used in choosing between a VKA or a NOAC, alcohol intake, blood pressure variability, or comorbidities such as renal disease, which we could not fully account for. These may be of some concern especially as NOACs are contraindicated in some settings. Two registries did not enroll every patient with OAC-ICH; exclusion of severe ICH might have caused ascertainment bias, but in our post hoc sensitivity analysis this did not affect 90-day mortality.

Our reported 90 -day mortality (31\%) is lower than some previous series of anticoagulant-related ICH (range $46 \%-68 \%)^{18}$ although similar to that reported in a recent German multicenter registry study (28\%). ${ }^{5}$ Follow-up duration and ICH mortality varied between centers; although we used a shared frailty model, this cannot fully account for all between-center heterogeneity. We acknowledge some measurement heterogeneity due to 2 different methods for rating $\mathrm{ICH}$ volumes, but ensured that each center rated both VKA-ICH and NOAC-ICH using the same method. Furthermore, adjusting for this heterogeneity in sensitivity analysis did not alter the primary result. Finally, hematoma expansion data were only available in $188 / 500$ patients, and were more often available in NOAC-ICH, so might not be generalizable to the entire cohort.

Our finding that $\mathrm{ICH}$ volume, $\mathrm{HE}$, and functional outcomes were similar for NOAC-ICH and VKA-ICH might have implications for clinical practice. NOACs have a lower risk of ICH than VKA for ischemic stroke prevention in populations with AF. ${ }^{1}$ Reversal agents for NOAC-related hemorrhage, including NOAC-ICH, have been developed, and are likely to become more widely available (although these agents are not yet established as clinically effective in patients with NOAC-ICH). ${ }^{19-22}$ Our study therefore does not support previous concerns that NOAC-ICH might have poorer outcome than VKA-ICH because of a lack of available specific reversal agents. ${ }^{2,3}$ Nevertheless, further randomized data for detailed NOAC-ICH functional outcome and radiologic profiles compared to VKA-ICH are 
needed. Furthermore, little is known about the risk of NOAC-ICH or its functional outcome in patients at high risk of $\mathrm{ICH}$, e.g., those with previous $\mathrm{ICH}$ or with bleeding-prone arteriopathies. ${ }^{23}$ As specific NOAC-ICH reversal agents become available, studies of how these affect clinical and radiologic outcomes are needed. Other treatment options for NOAC$\mathrm{ICH}$, including hemostatic agents ${ }^{24}$ and acute blood pressure management, ${ }^{25}$ also need to be investigated, ideally in randomized controlled trials.

\section{AUTHOR CONTRIBUTIONS}

D.W. was involved in study concept, study design, data acquisition, and statistical analysis and drafted the manuscript. D.J.S. was involved in data acquisition and revised the manuscript. C.T. was involved in data acquisition and revised the manuscript. G.B. was involved in data acquisition and revised the manuscript. J.C.P. was involved in data acquisition and revised the manuscript. T.R. was involved in data acquisition and revised the manuscript. O.A.S. was involved in data acquisition and revised the manuscript. H.S. was involved in data acquisition and revised the manuscript. S.-J.Y. was involved in data acquisition and revised the manuscript. T.Y.W. was involved in data acquisition and revised the manuscript. M.F. was involved in data acquisition and revised the manuscript. R.H. was involved in data acquisition and revised the manuscript. F.H.B.M.S. was involved in data acquisition and revised the manuscript. L.A.P. was involved in data acquisition and revised the manuscript. J.T. was involved in data acquisition and revised the manuscript. M.B. was involved in data acquisition and revised the manuscript. R.A.-S.S. was involved in data acquisition and revised the manuscript. H.R.J. was involved in data acquisition and revised the manuscript. G.A. was involved in statistical analysis and revised the manuscript. C.S. was involved in data acquisition and revised the manuscript. Y.Y. was involved in data acquisition and revised the manuscript. P.M.C.C. was involved in data acquisition and revised the manuscript. J.S. was involved in data acquisition and revised the manuscript. C.C. was involved in data acquisition and revised the manuscript. J.-S.J. was involved in data acquisition and revised the manuscript. R.V. was involved in data acquisition and revised the manuscript. D.D. was involved in data acquisition and revised the manuscript. S.T.E. was involved in data acquisition and revised the manuscript. A.R.P.-J. was involved in study design and data acquisition and drafted the manuscript. A.M. was involved in study design, data acquisition, and statistical analysis and revised the manuscript. D.J.W. was involved in study concept, design, data acquisition, statistical analysis, and manuscript revision.

\section{ACKNOWLEDGMENT}

The authors thank all the principal investigators and research practitioners involved in the CROMIS-2 study, which was supported by the NIHR Clinical Research Network.

\section{STUDY FUNDING}

D.J.W. receives research support from the Stroke Association, British Heart Foundation, and the Rosetrees Trust. D.W. receives research support from the Stroke Association and British Heart Foundation. This work was undertaken at UCLH/UCL, which received a proportion of funding from the Department of Health's NIHR Biomedical Research Centers funding scheme. G.A. receives funding from the National Institute for Health Research University College London Hospitals Biomedical Research Center. D.J.S., C.T., and S.T.E. received funding from the Swiss Heart Foundation for the conductance of the NOACISP registry. A.M. receives funding from the National Health and Medical Research Council, Australia, and the Academy of Finland. R.A.-S.S. was funded by a MRC senior clinical fellowship.

\section{DISCLOSURE}

D. Wilson reports no disclosures relevant to the manuscript. D. Seiffge received funding from the Swiss Heart Foundation. C. Traenka received funding from the Swiss Heart Foundation. G. Basir reports no disclosures relevant to the manuscript. J. Purrucker received personal fees from Boehringer Ingelheim and Pfizer outside the submitted work. T. Rizos has received consulting honoraria, speaker's honoraria, and travel support from BMS Pfizer, Boehringer Ingelheim, Bayer health care, and Daiichi Sankyo. D. Dowlatshahi holds funding from the Canadian Institutes of Health Research, has received an unrestricted education grant from Octapharma Canada, and has received honoraria from Bayer Canada and BMS-Pfizer, all outside of the submitted work. O. Sobowale reports no disclosures relevant to the manuscript. H. Sallinen, S. Yeh, T. Wu, M. Ferrigno, R. Houben, F. Schreuder, L. Perry, J. Tanaka, M. Boulanger, R. Al-Shahi Salman, H. Jäger, G. Ambler, C. Shakeshaft, Y. Yakushiji, P. Choi, J. Staals, C. Cordonnier, J. Jeng, R. Veltkamp, and D. Dowlatshahi report no disclosures relevant to the manuscript. S. Engelter received funding for travel or speaker honoraria from Bayer and Boehringer Ingelheim, has served on scientific advisory boards for Bayer, Boehringer Ingelheim, and BMS/Pfizer, has received an educational grant from Pfizer, and received funding from the Swiss Heart Foundation for the conductance of the NOACISP registry. A. Parry-Jones reports no disclosures relevant to the manuscript. A. Meretoja received consulting fees, speaker honoraria, and travel support from Boehringer Ingelheim and Stryker, outside the submitted work. D. Werring received personal fees from Bayer outside the submitted work. Go to Neurology.org for full disclosures.

Received July 10, 2016. Accepted in final form January 18, 2017.

\section{REFERENCES}

1. Ruff CT, Giugliano RP, Braunwald E, et al. Comparison of the efficacy and safety of new oral anticoagulants with warfarin in patients with atrial fibrillation: a meta-analysis of randomised trials. Lancet 2014;383:955-962.

2. Ansell J. New oral anticoagulants should not be used as first-line agents to prevent thromboembolism in patients with atrial fibrillation. Circulation 2012;125: 165-170.

3. Schulman S, Majeed A. The oral thrombin inhibitor dabigatran: strengths and weaknesses. Semin Thromb Hemost 2012;38:7-15.

4. Parry-Jones AR, Di Napoli M, Goldstein JN, et al. Reversal strategies for vitamin $\mathrm{K}$ antagonists in acute intracerebral hemorrhage. Ann Neurol 2015;78:54-62.

5. Purrucker JC, Haas K, Rizos T, et al. Early clinical and radiological course, management, and outcome of intracerebral hemorrhage related to new oral anticoagulants. JAMA Neurol 2016;73:169-177.

6. Hart RG, Diener HC, Yang S, et al. Intracranial hemorrhage in atrial fibrillation patients during anticoagulation with warfarin or dabigatran: the RE-LY trial. Stroke 2012; 43:1511-1517.

7. Hankey GJ, Stevens SR, Piccini JP, et al. Intracranial hemorrhage among patients with atrial fibrillation anticoagulated with warfarin or rivaroxaban: the rivaroxaban once daily, oral, direct factor Xa inhibition compared with vitamin $\mathrm{K}$ antagonism for prevention of stroke and embolism trial in atrial fibrillation. Stroke 2014; 45:1304-1312.

8. Held C, Hylek EM, Alexander JH, et al. Clinical outcomes and management associated with major bleeding in patients with atrial fibrillation treated with apixaban or warfarin: insights from the ARISTOTLE trial. Eur Heart J 2015;36:1264-1272.

9. Hagii J, Tomita H, Metoki N, et al. Characteristics of intracerebral hemorrhage during rivaroxaban treatment: comparison with those during warfarin. Stroke 2014;45: 2805-2807.

10. Wilson D, Charidimou A, Shakeshaft C, et al. Volume and functional outcome of intracerebral hemorrhage 
according to oral anticoagulant type. Neurology 2016;86: 360-366.

11. Hallevi H, Dar NS, Barreto AD, et al. The IVH score: a novel tool for estimating intraventricular hemorrhage volume: clinical and research implications. Crit Care Med 2009;37:969-974, e961.

12. Morgan TC, Dawson J, Spengler D, et al. The modified Graeb score: an enhanced tool for intraventricular hemorrhage measurement and prediction of functional outcome. Stroke 2013;44:635-641.

13. Dowlatshahi D, Demchuk AM, Flaherty ML, et al. Defining hematoma expansion in intracerebral hemorrhage: relationship with patient outcomes. Neurology 2011;76:1238-1244.

14. Zhou W, Zorn M, Nawroth P, et al. Hemostatic therapy in experimental intracerebral hemorrhage associated with rivaroxaban. Stroke 2013;44:771-778.

15. Lauer A, Cianchetti FA, Van Cott EM, et al. Anticoagulation with the oral direct thrombin inhibitor dabigatran does not enlarge hematoma volume in experimental intracerebral hemorrhage. Circulation 2011;124:1654-1662.

16. Akiyama H, Uchino K, Hasegawa Y. Characteristics of symptomatic intracranial hemorrhage in patients receiving non-vitamin $\mathrm{K}$ antagonist oral anticoagulant therapy. PloS One 2015;10:e0132900.

17. Hankey GJ. Intracranial hemorrhage and novel anticoagulants for atrial fibrillation: what have we learned? Curr Cardiol Rep 2014;16:480.
18. Hart RG, Boop BS, Anderson DC. Oral anticoagulants and intracranial hemorrhage. Facts and hypotheses. Stroke 1995;26:1471-1477.

19. Glund S, Stangier J, Schmohl M, et al. Safety, tolerability, and efficacy of idarucizumab for the reversal of the anticoagulant effect of dabigatran in healthy male volunteers: a randomised, placebo-controlled, double-blind phase 1 trial. Lancet 2015;386:680-690.

20. Siegal DM, Curnutte JT, Connolly SJ, et al. Andexanet alfa for the reversal of factor Xa inhibitor activity. New Engl J Med 2015;373:2413-2424.

21. Schiele F, van Ryn J, Canada K, et al. A specific antidote for dabigatran: functional and structural characterization. Blood 2013;121:3554-3562.

22. Pollack CV Jr, Reilly PA, Eikelboom J, et al. Idarucizumab for dabigatran reversal. New Engl J Med 2015;373: 511-520.

23. Hofmeijer J, Kappelle LJ, Klijn CJ. Antithrombotic treatment and intracerebral haemorrhage: between scylla and charybdis. Pract Neurol 2015;15:250-256.

24. Sprigg N, Renton CJ, Dineen RA, Kwong Y, Bath PM. Tranexamic acid for spontaneous intracerebral hemorrhage: a randomized controlled pilot trial (ISRCTN50867461). J Stroke Cerebrovasc Dis 2014;23:1312-1318.

25. Anderson CS, Heeley E, Huang Y, et al. Rapid bloodpressure lowering in patients with acute intracerebral hemorrhage. New Engl J Med 2013;368:2355-2365.

\section{This Week's Neurology ${ }^{\circledR}$ Podcast}

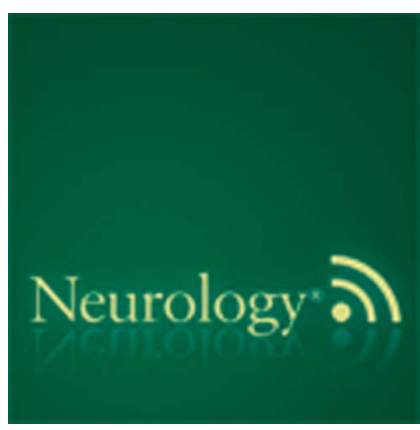

Outcome of intracerebral hemorrhage associated with different oral anticoagulants (see p. 1693)

This podcast begins and closes with Dr. Robert Gross, Editor-inChief, briefly discussing highlighted articles from the May 2, 2017, issue of Neurology. In the first segment, Dr. Andy Southerland interviews Dr. David Werring about the association between intracerebral hemorrhage outcome and different oral anticoagulants. In the next segment, Dr. Michelle Mauermann talks with Dr. Rodica Pop-Busui about a Neurology Today ${ }^{\circledR}$ feature on preventing, diagnosing, and treating diabetic neuropathy for our "What's Trending" feature of the week.

Disclosures can be found at Neurology.org.

At Neurology.org, click on "RSS" in the Neurology Podcast box to listen to the most recent podcast and subscribe to the RSS feed.

CME Opportunity: Listen to this week's Neurology Podcast and earn 0.5 AMA PRA Category

1 CME Credits ${ }^{\mathrm{TM}}$ by answering the multiple-choice questions in the online Podcast quiz. 


\section{Neurology}

Outcome of intracerebral hemorrhage associated with different oral anticoagulants

Duncan Wilson, David J. Seiffge, Christopher Traenka, et al.

Neurology 2017;88;1693-1700 Published Online before print April 5, 2017

DOI 10.1212/WNL.0000000000003886

This information is current as of April 5, 2017

Neurology ${ }^{\circledR}$ is the official journal of the American Academy of Neurology. Published continuously since 1951, it is now a weekly with 48 issues per year. Copyright Copyright $@ 2017$ The Author(s). Published by Wolters Kluwer Health, Inc. on behalf of the American Academy of Neurology.. All rights reserved. Print ISSN: 0028-3878. Online ISSN: 1526-632X.

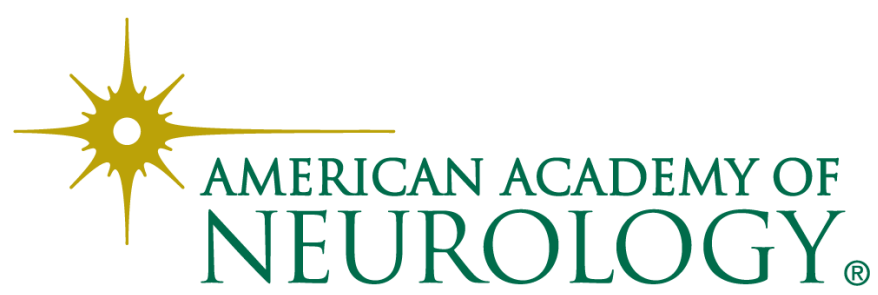




\section{Updated Information \& Services}

\section{Supplementary Material}

\section{References}

Citations

Subspecialty Collections

\section{Errata}

\section{Permissions \& Licensing}

\section{Reprints}

including high resolution figures, can be found at: http://n.neurology.org/content/88/18/1693.full

Supplementary material can be found at: http://n.neurology.org/content/suppl/2017/04/05/WNL.0000000000003 886.DC1

http://n.neurology.org/content/suppl/2017/04/05/WNL.0000000000003 886.DC2

http://n.neurology.org/content/suppl/2017/04/05/WNL.0000000000003 886.DC3

http://n.neurology.org/content/suppl/2017/05/01/WNL.0000000000003 886.DC4

This article cites 25 articles, 12 of which you can access for free at: http://n.neurology.org/content/88/18/1693.full\#ref-list-1

This article has been cited by 2 HighWire-hosted articles: http://n.neurology.org/content/88/18/1693.full\#\#otherarticles

This article, along with others on similar topics, appears in the following collection(s):

Clinical trials Observational study (Cohort, Case control)

http://n.neurology.org/cgi/collection/clinical_trials_observational_study _cohort_case_control

CT

http://n.neurology.org/cgi/collection/ct

Intracerebral hemorrhage

http://n.neurology.org/cgi/collection/intracerebral_hemorrhage

Outcome research

http://n.neurology.org/cgi/collection/outcome_research

Prognosis

http://n.neurology.org/cgi/collection/prognosis

An erratum has been published regarding this article. Please see next page or:

/content/90/23/1084.3.full.pdf

Information about reproducing this article in parts (figures,tables) or in its entirety can be found online at:

http://www.neurology.org/about/about_the_journal\#permissions

Information about ordering reprints can be found online:

http://n.neurology.org/subscribers/advertise

Neurology ${ }^{\circledR}$ is the official journal of the American Academy of Neurology. Published continuously since 1951, it is now a weekly with 48 issues per year. Copyright Copyright ( 2017 The Author(s). Published by Wolters Kluwer Health, Inc. on behalf of the American Academy of Neurology.. All rights reserved. Print ISSN: 0028-3878. Online ISSN: 1526-632X.

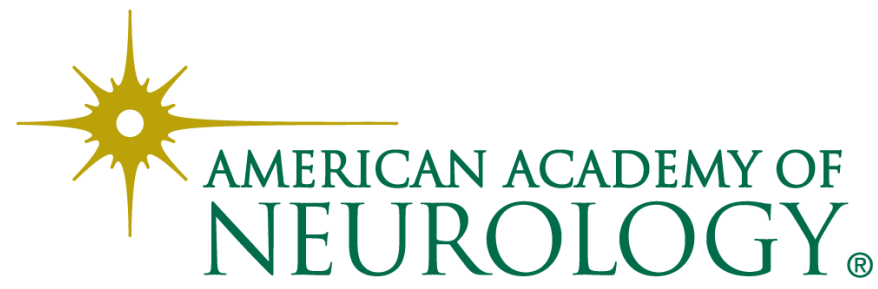




\section{Quinidine-associated skin discoloration in KCNT1-associated pediatric epilepsy}

Neurology ${ }^{\circledR}$ 2018;90:1084. doi:10.1212/WNL.0000000000005628

In the NeuroImage "Quinidine-associated skin discoloration in KCNT1-associated pediatric epilepsy" by Baumer and Sheehan, ${ }^{1}$ there is an error in the second to last sentence, which should have referred to ezobagine and quinine as potassium channel agents rather than potassium channel blockers as originally published. The authors regret the error.

\section{Reference}

1. Baumer FM, Sheehan M. Quinidine-associated skin discoloration in KCNT1-associated pediatric epilepsy. Neurology 2017;89:2212.

\section{The genetic basis of undiagnosed muscular dystrophies and myopathies: Results from 504 patients}

Neurology ${ }^{\circledR}$ 2018;90:1084. doi:10.1212/WNL.0000000000005192

In the article "The genetic basis of undiagnosed muscular dystrophies and myopathies: Results from 504 patients" by M. Savarese et al., ${ }^{1}$ there is an error in the 21st author's name, which should have read "Simone Sampaolo" rather than "Simone Sanpaolo" as originally published. The authors regret the error.

\section{Reference}

1. Savarese M, Di Fruscio G, Torella A, et al. The genetic basis of undiagnosed muscular dystrophies and myopathies: Results from 504 patients. Neurology 2016;87:71-76.

\section{Outcome of intracerebral hemorrhage associated with different oral anticoagulants \\ Neurology ${ }^{\circledR}$ 2018;90:1084. doi:10.1212/WNL.0000000000004976}

In the article "Outcome of intracerebral hemorrhage associated with different oral anticoagulants" by D. Wilson et al., ${ }^{1}$ there are typographical errors in the rate of hematoma expansion within the study cohorts. The second to last sentence of the Abstract should read "...the rate of HE (NOAC-ICH n $=19 / 48$ [40\%] vs VKA-ICH n $=47 / 140$ [34\%])" rather than "29/48 [40\%]" and "93/140 [34\%]," respectively, as originally published. Likewise, the third sentence under "Secondary outcomes" in the Results section should read "... and did not vary by anticoagulant type (NOAC-ICH 19/48 40\% vs VKA-ICH 47/140 34\%, $p=0.45$ )” rather than " $29 / 4840 \%$ " and "93/140 34\%" as originally published. The authors regret the errors.

\section{Reference}

1. Wilson D, Seiffge DJ, Traenka C, et al. Outcome of intracerebral hemorrhage associated with different oral anticoagulants. Neurology 2017;88:1693-1700. 